\title{
Lipolysis Produces Changes in the Immunoreactivity and Cell Reactivity of Very Low Density Lipoproteins
}

\author{
G. Schonfeld, W. Patsch, B. Pfleger, J. L. Witztum, and S. W. Weidman, \\ Lipid Research Center, Departments of Preventive Medicine and Medicine, \\ Washington University School of Medicine, St. Louis, Missouri 63110
}

A B S T RACT Smaller very low density lipoprotein (VLDL) remnants interact more readily with tissues than do larger "intact" VLDL. This may be related to changes in the availability of VLDL apoproteins on the surface of the lipoproteins. To test this hypothesis VLDL were incubated at $37^{\circ} \mathrm{C}$ with bovine milk lipase (LPL), and the abilities of LPL-treated VLDL preparations to compete with ${ }^{125} \mathrm{I}$-low density lipoproteins (LDL) for interaction with cultured normal human fibroblasts were measured. At the same time, the immunologic activities of these preparations were also tested by double antibody radioimmunoassay. Triglyceride (TG) contents of VLDL fell by $30-90 \%$ during incubation with LPL and, on zonal ultracentrifugation, VLDL of faster Svedberg unit of flotation $\left(S_{\mathbf{f} 1.063}\right)$ rates $(>150)$ were gradually converted to smaller VLDL with lower $S_{f}$ rates (21-60). LPL-treated VLDL competed two to five times more effectively with ${ }^{125}$ I-LDL for binding to cellular receptors than did control VLDL. Control VLDL incubated with heat-inactivated $L P L$ at $37^{\circ} \mathrm{C}$, or with active LPL at $4^{\circ} \mathrm{C}$ had unaltered cell reactivities and TG contents compared with VLDL incubated without any enzyme. The direct uptake and degradation of LPLtreated VLDL was also assessed by using VLDL ${ }^{125} \mathrm{I}-$ labeled in apoprotein (Apo)B. LPL-treated VLDL${ }^{125} \mathrm{I}$-ApoB were taken up and degraded by fibroblast at greater rates than were control VLDL-125I-ApoB. Thus, hydrolysis of VLDL lipids was accompanied by an increased ability of VLDL to interact with fibroblasts. The immunoreactivity of ApoB in the same VLDL preparations, expressed as the "apparent ApoB contents" of LPL-treated VLDL, increased by $10-50 \%$ $(P<0.02)$ in those assays that contained anti-LDL antisera, but the ApoB of control VLDL remained constant. However, assays that contained antisera directed against ApoB isolated from VLDL did not distinguish

Received for publication 7 August 1978 and in revised form 9 July 1979. between LPL-treated and control VLDL. Thus, VLDL lipid hydrolysis was accompanied by changes in the immunoreactivity of VLDL-ApoB, which probably reflect changes in the disposition of $A p o B$ on the surface of VLDL. The altered disposition of ApoB on VLDL "remnants" may be related to their enhanced interaction with cells.

\section{INTRODUCTION}

Very low density lipoproteins (VLDL) ${ }^{1}$ are secreted by the liver as spherical particles that consist of lipids and apoproteins, and chylomicrons and VLDL are secreted by the gut $(1,2)$. Upon entering the plasma compartment, these triglyceride (TG)-rich particles undergo a series of transformations by means of which they are converted progressively to smaller particles-called intermediate density lipoproteins or remnants - and finally to low density lipoproteins (LDL) $(3,4)$. During catabolism there are net losses of both core and surface components, e.g., TG and phospholipids, respectively $(5,6)$. Apoproteins (Apo)C and $E$ too are lost, but $A p o B$ remains with the remnants.

VLDL remnants are taken up more rapidly by cells in culture than are large VLDL particles (7), and chylomicron remnants are removed much more rapidly from the circulation by liver in vivo $(8,9)$ and in vitro $(10,11)$ than are chylomicrons. Thus, partial lipolysis of the TG-rich lipoproteins appears to be necessary for their efficient uptake by cells. This is true for both human and animal lipoproteins (12).

The uptake of human and animal LDL by fibroblasts and other cells occurs by adsorptive endocytosis via a

${ }^{1}$ Abbreivations used in this paper: Apo, apoprotein(s); Chol, cholesterol; HDL, high density lipoprotein(s); LDL, low density lipoprotein(s); LPDS, lipoprotein-deficient serum; LPL, bovine milk lipase; PL, phospholipid(s); $S_{f}$, Svedberg unit(s) of flotation; TG, triglyceride(s); TMU, tetramethyl urea; VLDL, very low density lipoprotein(s). 
specific LDL receptor that is located in coated pits on the surfaces of cells (13). The LDL receptor recognizes two apoproteins-ApoB $(14,15)$ and ApoE (16) - both of which are contained on VLDL and chylomicrons isolated from human plasma (17). Human LDL ( $d$ 1.0251.050) contain only ApoB (18). The enhanced reactivity of remnants with cells could be a result of several changes which accompany remnant formation: (a) As larger lipoproteins are converted to smaller remnants, steric hindrance to their interactions with cellular receptors could be reduced. $(b)$ The selective retention of ApoB in remnants could "concentrate" ApoB over the surfaces of the lipoproteins. (c) The conformations of binding sites of apoproteins could be altered as the surface areas of the lipoproteins are reduced. (d) Binding sites on apoproteins could be unmasked as a consequence of the removal of lipids or proteins from lipoprotein surfaces. It is difficult, by techniques available at this time, to distinguish among all of these possibilities. However, immunologic techniques do allow one to assess the immunoreactivities of individual lipoprotein-associated apoproteins (19), and to ascertain whether the immunologically active regions on apoprotein molecules are altered during lipoprotein catabolism. At the same time, the interactions of the lipoproteins with cellular receptors can be assessed. The aim of this work was to ascertain whether the immunoreactivity of $\mathrm{ApoB}$, a major protein in VLDL, was altered during the course of VLDL lipid hydrolysis and to assess whether this immunologic change coincided with any alterations in the ability of VLDL to interact with the LDL receptor on cells.

\section{METHODS}

VLDL were isolated from plasma by ultracentrifugation in swinging bucket (SW40, SW27) or zonal (Ti 14) rotors in a Beckman L265B ultracentrifuge (Beckman Instruments, Inc., Spinco Div., Palo Alto, Calif.) in salt gradients $(20,21)$. Svedberg unit of flotation $\left(S_{f}\right)>100$ fractions from swinging buckets and $S_{f}>150$ fractions from zonal rotors were used as starting materials for bovine milk lipase (LPL) digestions. Swinging bucket fractions were purified by column filtration as follows: 1-ml VLDL aliquots, containing $\cong 2-3 \mathrm{mg}$ of VLDL protein, were filtered on $0.7 \times 40$ - or $60-\mathrm{cm}$ columns of Sepharose 2B (Pharmacia Fine Chemicals, Inc., Piscataway, N. J.) ( $1 \mathrm{mM}$ EDTA, $0.16 \mathrm{M} \mathrm{NaCl}, \mathrm{pH} 7.4)$. VLDL eluted in the first peak $(280 \mathrm{~nm})$. Zonal fractions were purified by recentrifugation in the zonal rotor under the same conditions used for the original isolations.

To produce VLDL remnants, aliquots of VLDL $(\cong 0.5 \mathrm{mg}$ protein $/ \mathrm{ml}$ ) were incubated at $37^{\circ} \mathrm{C}$ in Krebs-Ringer bicar-

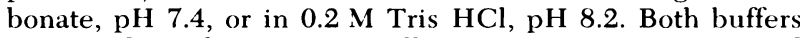
contained $10 \%$ bovine serum albumin (Fraction V, Fatty Acid Free, Miles Laboratories, Inc., Elkhart, Ind.). Bovine milk lipoprotein lipase (prepared by heparin-Sepharose 4B affinity chromatography [22], specific activity: 175-405 $\mu \mathrm{mol} \mathrm{FFA} / \mathrm{h}$ per $\mathrm{ml}$ ) was added, and incubations were carried out for up to $10 \mathrm{~h}$. Control VLDL were incubated at $4^{\circ} \mathrm{C}$ with active LPL, at $37^{\circ} \mathrm{C}$ in the presence of inactivated LPL $\left(50^{\circ} \mathrm{C}\right.$ for $1 \mathrm{~h}$ or $23^{\circ} \mathrm{C}$ for $24 \mathrm{~h}$ ), or at $37^{\circ} \mathrm{C}$ in the absence of LPL. All of these controls gave identical results. At the end of incubation, tubes were placed on ice, and samples were taken for determination of levels of ApoB and TG, and for incubation with cultured human fibroblasts. In selected instances, LPL-treated VLDL and control VLDL were refiltered on the Sepharose columns or subjected to zonal ultracentrifugation. These fractions were analyzed for their contents of apoproteins and lipids and also incubated with cells.

TG and cholesterol (Chol) analyses were performed on chloroform-methanol extracts (23). Aliquots of organic phase, which had been "washed" with $0.15 \mathrm{M} \mathrm{NaCl}$, were dried under $\mathrm{N}_{2}$, redissolved in isopropanol, and, after addition of zeolite, processed on an AutoAnalyzer II (Technicon Instruments Corp., Tarrytown, N. Y.) (24). TG, free, and esterified Chol were also determined enzymatically $(25,26)$ (Boehringer Triglyceride Kit 126012 and Cholesterol Kit 124087, Boehringer Mannheim Biochemicals, Indianapolis, Ind.). Phospholipids (PL) were measured by the method of Bartlett (27) on chloroform-methanol extracts (23). Protein was determined by the Bensadoun and Weinstein modification (28) of the method of Lowry et al. (29). Isoelectric focusing was done according to Weidman et al. (30).

The immunologic reactivities of the ApoB in VLDL preparations were evaluated in double antibody radioimmunoassays (31), using ${ }^{125}$ I-LDL ( $d$ 1.025-1.050) labeled with chloramine-T as tracer, and LDL as standard. Antisera were produced in rabbits either against intact $\operatorname{LDL}(d 1.025-1.050)$, or against ApoB isolated from VLDL by column chromatography on $2.5 \times 90-\mathrm{cm}$ columns of Sephadex G200 (Pharmacia Fine Chemicals, Inc.), $0.05 \mathrm{M}$ Tris, $\mathrm{pH} 8.6,8 \mathrm{M}$ urea, $1 \mathrm{mM}$ $\mathrm{Na}$ decyl sulfate $(32,33)$. ApoB was in peak 1 (18). The ApoB content of VLDL fractions was also assessed by the method of Kane et al. $(34,35)$ using tetramethyl urea (TMU). AntiApoE antisera were produced against peak 2 of the Sephadex G200 column which had been repurified on the same column. ApoE migrated as a single band of $\cong 35,000 \mathrm{~mol}$ wt on sodium dodecyl sulfate gel electrophoresis (36). Antirabbit IgG was produced in goats.

Normal fibroblasts were derived from skin explants taken from a 3-mo-old male, a 33-yr-old male, and a 40-yr-old female. All normal lines gave similar results. Cell culture was as described by Goldstein and Brown (37) and Ostlund et al. (38). Fibroblasts were grown for $6 \mathrm{~d}$ in $2 \mathrm{ml}$ of Eagle's minimum essential medium (Gibco Diagnostics, Chagrin Falls, Ohio) that contained $50 \mu \mathrm{g} / \mathrm{ml}$ streptomycin, $50 \mathrm{U} / \mathrm{ml}$ penicillin, $1.24 \mu \mathrm{g} / \mathrm{ml}$ amphotericin B (Fungizone, E. R. Squibb \& Sons, Princeton, N. J.), and 15\% fetal bovine serum (Gibco Diagnostics). The medium was then changed to $1 \mathrm{ml}$ of Eagle's medium that contained antibiotics and $2.5 \mathrm{mg} / \mathrm{ml}$ human lipoprotein-deficient serum (LPDS), for $24 \mathrm{~h}$ before any experiment.

At the beginning of experiments, the LPDS-containing medium was removed, and each $35-\mathrm{mm}$ dish received $1 \mathrm{ml}$ of fresh medium (LPDS) that contained $5 \mu \mathrm{g} / \mathrm{ml}{ }^{125} \mathrm{I}-\mathrm{LDL}$ iodinated with iodine monochloride to specific radioactivity $\cong 100 \mathrm{cpm} / \mathrm{ng}(39,40)$ and the appropriate control or LPLtreated VLDL preparation. In one experiment, $5 \mu \mathrm{g} / \mathrm{ml} \mathrm{VLDL-}$ ${ }^{125} \mathrm{I}-\mathrm{ApoB}$ was added directly. The cells were incubated at $4^{\circ}$ or $37^{\circ} \mathrm{C}$ for $4 \mathrm{~h}$, after which the experiment was terminated by removal of the medium and placement of the dishes on ice. The cells were washed (38) and dissolved in $1 \mathrm{ml}$ of $0.1 \mathrm{~N}$ $\mathrm{NaOH}$ for determination of cell-accumulated ${ }^{25}$ I-LDL. At $4^{\circ} \mathrm{C}$, these cell-associated counts represent ${ }^{125} \mathrm{I}-\mathrm{LDL}$ bound to the cell receptors; at $37^{\circ} \mathrm{C}$, the counts represent both cellreceptor bound and intracellular ${ }^{125}$ I-LDL. ${ }^{125}$ I-LDL degradation products, soluble in $10 \% \mathrm{TCA}$, were determined in the removed culture medium $(37,38)$. Blank dishes that contained culture medium and ${ }^{125}$ I-LDL but no cells were routinely 


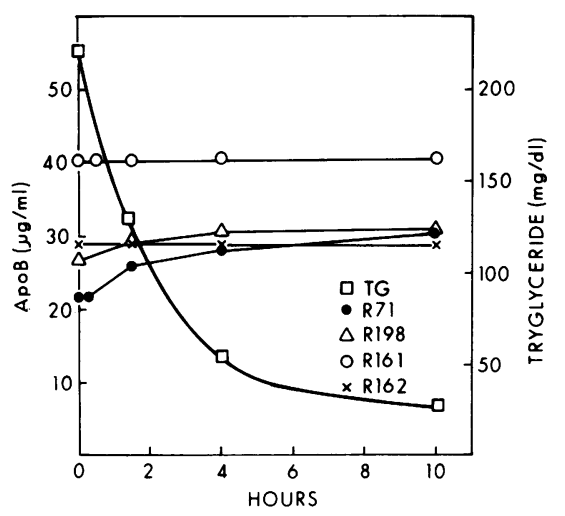

FIGURE 1 Effect of lipolysis on the apparent concentrations of ApoB inVLDL isolated by zonal ultracentrifugation. $4.1 \mathrm{mg}$ (determined as VLDL protein) of an $S_{f}>150$ VLDL fraction isolated from a hypertriglyceridemic plasma (see peak $a$, zero min in Fig. 2) was incubated at $37^{\circ} \mathrm{C}$ with $1.5 \mathrm{ml}$ of LPL (specific activity: $175 \mu \mathrm{mol} \mathrm{FFA} / \mathrm{h}$ per $\mathrm{ml}$ ) in $0.2 \mathrm{M}$ Tris, $\mathrm{pH} 8.2$, $9 \%$ bovine serum albumin for up to $10 \mathrm{~h}$. Total incubated volume was $30 \mathrm{ml}$. At the indicated times, aliquots were removed for determinations of TG and $\mathrm{ApoB}$ and for zonal ultracentrifugation (Fig. 2). R71 and R198 are anti-LDL antisera. $\mathrm{R} 161$ and R162 are anti-VLDL-ApoB antisera.

employed. Noniodide TCA-soluble counts observed in blank dishes were subtracted from those of experimental dishes. Cell protein was determined by the method of Lowry et al. (29).

\section{RESULTS}

Lipolysis of VLDL. When VLDL were incubated with LPL, TG was progressively lost in all preparations. Some lost greater proportions of their TG contents than others over a 2 -h incubation. Losses ranged from 30 to $90 \%$ of initial TG contents (Figs. 1 and 2, Table I). In the swinging bucket $S_{\mathrm{f}}>100$ VLDL preparation, $\cong 20 \%$ of the TG was hydrolyzed in $15 \mathrm{~min}$ and $\cong 90 \%$ in $2 \mathrm{~h}$ (not shown). In the zonal rotor $\mathrm{S}_{\mathrm{f}}>150$ preparation (Fig. 1) , 7, 42, 76, and $89 \%$ of TG were hydrolyzed at $15,90,240$, and $600 \mathrm{~min}$, respectively.

LPL treatment of VLDL resulted in the production of materials with markedly changed $S_{f}$ rates (Fig. 2). As TG hydrolysis progressed, the $S_{\mathrm{f}}$ rate of the starting VLDL population dropped from $\mathrm{S}_{\mathrm{f}}>150$ (peak $a$, zero time) to $\mathrm{S}_{\mathrm{f}}>130$ (peak $b, 90 \mathrm{~min}$ ) and to $\mathrm{S}_{\mathrm{f}}>95$ (peak $d$, $240 \mathrm{~min}$ ). A second population of VLDL also appeared. At 90 min (peak $c$ ) this peak had $S_{\mathrm{f}}$ rate of $\cong 75$ and at $240 \mathrm{~min}$ an $\mathrm{S}_{\mathrm{f}}$ rate of $\cong 50$ (peak $e$ ). By the end of incubation $(600 \mathrm{~min}$ ), the faster floating VLDL had disappeared and all of the VLDL was found in the $S_{f}$ 21-60 range (peak $f$ ). These determinations of $S_{\mathrm{f}}$ rates were carried out under rate zonal conditions. It was also possible to demonstrate under equilibrium conditions that the density of VLDL was altered by LPL treatment. Whereas $\cong 90 \%$ of the control VLDL-125I-ApoB

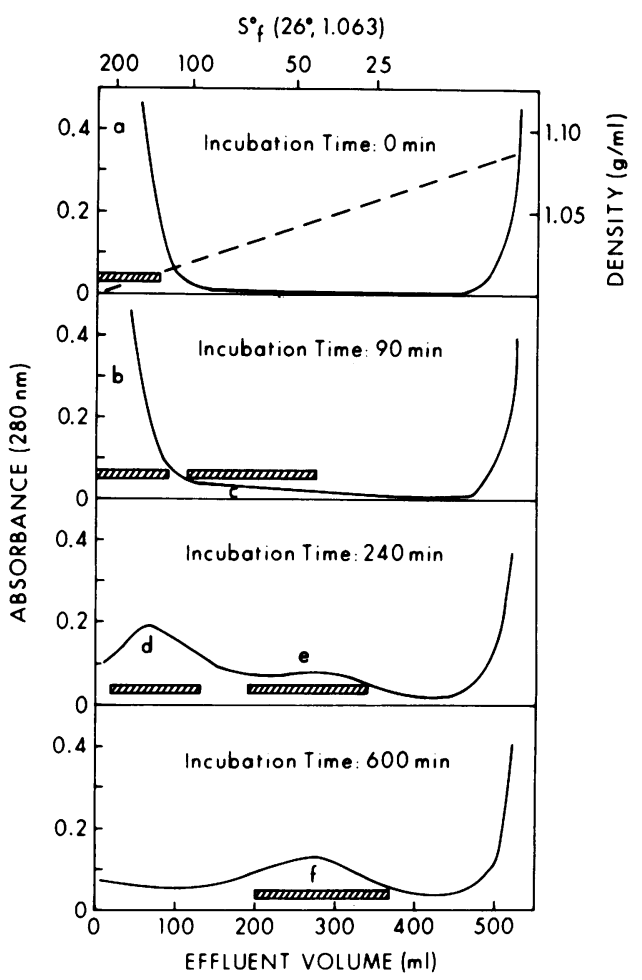

FIGURE 2 Effect of lipolysis on the flotation rate of $S_{f}\left(S^{\circ}{ }_{f 1.063}\right)$ $>150$ VLDL. The $S_{f}>150$ fraction (zero min, peak $a$ ) was incubated with LPL. Aliquots were removed at the indicated times and subjected to zonal ultracentrifugation under conditions described by Patsch et al. (21). The aliquots obtained at the various times were each spun under identical conditions. The tubes indicated by the labeled bars were pooled and tested for their reactivity with antisera and with cells.

(see Fig. 6) floated in the top $1 \mathrm{ml}$ of the tube after ultracentrifugation at $d 1.006$ for $20 \mathrm{~h}$ in a 65 rotor, only $2 \%$ of the LPL-treated VLDL- ${ }^{125}$ I-ApoB floated at $d$ 1.006 under identical conditions. The apparent Stokes radii of VLDL were also reduced by LPL treatment, i.e., on column chromatography the lipolyzed VLDL was more retarded on the column than was the starting material (not shown).

Lipolysis produced marked alterations in VLDL compositions. For example (Fig. 2), zonal peaks $a, d$, and $f$, respectively, contained $11.9,15.0$, and 18.6 percent dry weight PL; $68.7,53.8$, and 37.6 percent dry weight TG; $6.0,8.10$, and 11.9 percent dry weight proteins; and 7.1, 14.9, and 20 percent dry weight Chol esters. In these fractions, TMU-insoluble proteins represented from 32 to 48 and $61 \%$ of total proteins, respectively. Thus, lipolysis products were depleted of TG and enriched in Chol esters, protein (particularly ApoB), and PL.

Immunoreactivity of lipolyzed VLDL-ApoB. When as little as $\cong 20 \%$ of the TG of an $S_{f}>100$ swinging 
TABLE I

Alterations in VLDL-ApoB Immunoreactivity Produced by Lipoprotein Lipase

\begin{tabular}{|c|c|c|c|c|c|c|c|c|}
\hline \multirow{3}{*}{\multicolumn{2}{|c|}{ Incubation conditions }} & \multicolumn{6}{|c|}{ ApoB concentration } & \multirow{3}{*}{$\begin{array}{l}\text { TG concen- } \\
\text { tration }\end{array}$} \\
\hline & & \multicolumn{3}{|c|}{ Anti-LDL } & \multicolumn{3}{|c|}{ Anti-ApoB } & \\
\hline & & R71 & $\mathrm{R} 124$ & R198 & R161 & R162 & R83 & \\
\hline & & \multicolumn{6}{|c|}{$\mu g / m l$} & $\mu g / m l$ \\
\hline \multirow{3}{*}{ (a) } & VLDL alone $37^{\circ} \mathrm{C}$ & $93 \pm 8$ & & & $155 \pm 8$ & & & 2,050 \\
\hline & $\mathrm{VLDL}+\mathrm{LPL} 37^{\circ} \mathrm{C}$ & $112 \pm 3^{*}$ & & & $149 \pm 8$ & & & 700 \\
\hline & VLDL + LPL $4^{\circ} \mathrm{C}$ & $101 \pm 7$ & & & $144 \pm 18$ & & & 2,150 \\
\hline \multirow{2}{*}{ (b) } & VLDL alone $37^{\circ} \mathrm{C}$ & $157 \pm 6$ & $166 \pm 9$ & & $196 \pm 4$ & & $200 \pm 6$ & 1,490 \\
\hline & VLDL + LPL $37^{\circ} \mathrm{C}$ & $172 \pm 12^{*}$ & $167 \pm 12$ & & $187 \pm 4$ & & $201 \pm 6$ & 310 \\
\hline \multirow{3}{*}{ (c) } & VLDL alone $37^{\circ} \mathrm{C}$ & $109 \pm 4$ & $123 \pm 9$ & & $177 \pm 9$ & & & 2,840 \\
\hline & VLDL + LPL $37^{\circ} \mathrm{C}$ & $123 \pm 5^{*}$ & $137 \pm 9 *$ & & $169 \pm 16$ & & & 960 \\
\hline & VLDL + inactive LPL $37^{\circ} \mathrm{C}$ & $105 \pm 4$ & $114 \pm 5$ & & $173 \pm 15$ & & & 2,380 \\
\hline \multirow{3}{*}{ (d) } & VLDL alone $37^{\circ} \mathrm{C}$ & $67 \pm 5$ & & $60 \pm 2$ & & $62 \pm 4$ & & 1,290 \\
\hline & VLDL + LPL $37^{\circ} \mathrm{C}$ & $73 \pm 3 \ddagger$ & & $93 \pm 4 *$ & & $60 \pm 5$ & & 917 \\
\hline & VLDL + inactive LPL $37^{\circ} \mathrm{C}$ & $67 \pm 6$ & & $63 \pm 4$ & & $62 \pm 3$ & & 1,240 \\
\hline \multirow{3}{*}{ (e) } & VLDL alone $37^{\circ} \mathrm{C}$ & $44 \pm 3$ & & & $76 \pm 6$ & & & 1,090 \\
\hline & VLDL + LPL $37^{\circ} \mathrm{C}$ & $56 \pm 4^{*}$ & & & $74 \pm 5$ & & & 732 \\
\hline & VLDL + inactive LPL $37^{\circ} \mathrm{C}$ & $45 \pm 3$ & & & $73 \pm 6$ & & & 1,110 \\
\hline \multirow{2}{*}{$(f)$} & VLDL alone $37^{\circ} \mathrm{C}$ & $49 \pm 4$ & & & & $48 \pm 5$ & & 880 \\
\hline & VLDL + LPL $37^{\circ} \mathrm{C}$ & $77 \pm 6^{*}$ & & & & $43 \pm 4$ & & 377 \\
\hline
\end{tabular}

The ApoB contents of LPL-treated and control $S_{f}>100$ VLDL preparations were assessed at the end of the incubations by a radioimmunoassay specific for $A p o B$, using the indicated antisera, which were directed either against intact $L D L$ or against ApoB isolated from VLDL by column chromatography. Assays were run at five to seven doses in triplicate. Results are $\pm 1 \mathrm{SD} . \mathrm{S}_{\mathrm{f}}>100$ VLDL preparation $a, b, c, d, e$, and $f$ were isolated from the fasting plasmas of subjects with Types IV, IV, IV, II $a$, IV, and IV hyperlipidemia, respectively.

$* P<0.01$.

$\$ P<0.05$.

bucket VLDL fraction had been hydrolyzed, the ApoB concentrations of the LPL-containing incubation mixtures appeared to increase from 48 to $64 \mu \mathrm{g} / \mathrm{ml}$ $(P<0.01)$. Further hydrolysis of the lipids of this VLDL preparation did not increase its apparent contents of ApoB. This result was obtained in a radioimmunoassay that contained an anti-holo-LDL antiserum (R71). But in an assay run simultaneously that contained anti-ApoB antiserum (R161), the apparent contents of $\mathrm{ApoB}$ remained constant. No changes in apparent VLDL-ApoB contents were detected with either the anti-LDL or anti-ApoB antiserum in control incubations carried out with inactivated LPL. Analogous results were obtained with the $S_{f}>150$ zonally isolated VLDL incubated with LPL (Fig. 1). However, in this experiment, $10 \mathrm{~h}$ (rather than $2 \mathrm{~h}$ ) were required for $90 \%$ hydrolysis of TG. The ApoB contents of this mixture rose from 22 to $26 \mu \mathrm{g} / \mathrm{ml}$ when lipolysis was $\cong 30 \%$ complete, and to $31 \mu \mathrm{g} / \mathrm{ml}$ when 90\% lipolysis had been achieved. The VLDL subclasses of this incubation mixture were isolated by zonal ultracentrifugation and tested for immuno- reactivity. ApoB contents appeared to increase with the decreasing $S_{\mathrm{f}}$ rates (not shown).

The LPL-induced changes in TG levels and in the ApoB immunoreactivities of six other VLDL preparations are shown in Table I. Each of the VLDL preparations was assayed with one or more anti-LDL and one or more anti-ApoB antisera. In each case, when analyzed with the anti-LDL antiserum (R71, R124, R198), the LPL-treated VLDL appeared to contain more ApoB than did the non-LPL or the inactive LPL control VLDL, whereas the assays that contained anti-ApoB antisera (R83, R161, or R162) were not able to distinguish between the LPL-treated and control VLDL. Antiserum R161 appeared to detect more ApoB in the VLDL preparations than did other antisera.

It should be noted that these immunologic changes were not a result of any proteolytic activity of LPL (41). ${ }^{125} \mathrm{I}-\mathrm{LDL}$ was incubated with or without LPL at $37^{\circ} \mathrm{C}$ for $2 \mathrm{~h}$. $85-87 \%$ of the ${ }^{125}$ I counts were precipitable by $10 \%$ TCA in the LPL and $86 \%$ in the control incubations, respectively. The specificities of the radio immunoassays for ApoB should also be noted. The anti- 
TABLE II

Chemical Composition of VLDL Subfractions Isolated from Plasma by Zonal Ultracentrifugation

\begin{tabular}{lcrrrr}
\hline & FC $^{*}$ & \multicolumn{1}{c}{ CE 1} & \multicolumn{1}{c}{ TG } & PL & Protein \\
\hline \multicolumn{5}{c}{$\% d r y w t$} \\
VLDL $_{1}$ & 4.7 & \multicolumn{1}{c}{} & 78.1 & 9.5 & 7.6 \\
VLDL $_{2}$ & 4.4 & 6.4 & 70.7 & 10.7 & 7.7 \\
VLDL $_{3}$ & 5.1 & 12.2 & 61.2 & 12.6 & 8.7 \\
VLDL $_{4}$ & 6.0 & 11.8 & 56.5 & 14.7 & 10.9 \\
VLDL $_{5}$ & 7.0 & 16.2 & 48.4 & 15.9 & 12.3 \\
VLDL $_{6}$ & 7.1 & 20.1 & 44.5 & 16.4 & 11.9 \\
VLDL $_{7}$ & 7.7 & 24.9 & 35.7 & 16.6 & 14.8 \\
\hline
\end{tabular}

* FC, free chol; CE, cholesteryl esters.

\$ Linoleate was used to correct CE into cholesteryl esters.

LDL and anti-ApoB antisera used in these experiments bound $<5 \%$ of ${ }^{125} \mathrm{I}-\mathrm{ApoE}$, and in the assays unlabeled ApoE displaced $<1 \%$ as many ${ }^{125}$ I-LDL counts per unit protein mass as did unlabeled LDL.

LPL-induced changes in the immunoreactivity of VLDL-ApoE were also sought. These competitive assays contained ${ }^{125} \mathrm{I}$-ApoE, rabbit anti-human ApoE, VLDL, and goat antirabbit IgG in $0.05 \mathrm{M}$ barbital, pH 8.6, $3 \%$ bovine serum albumin. (Details of the ApoE assay will be published elsewhere.) In assays carried out with two different anti-ApoE antisera, the competitive displacement curves produced by LPLtreated and control VLDL were identical (not shown).

Characteristics of $S_{f}$ fractions isolated from plasma. We wished next to assess whether the LPL-altered immunoreactivities of VLDL-ApoB produced in vitro were reflected in vivo. Because particles with lower flotation rates are thought to be produced from particles with faster flotation rates in plasma by the action of LPL $(5,42)$, we isolated various $S_{f}$ fractions from plasma. Three VLDL subfractions, $S_{\mathrm{f}}>100, S_{\mathrm{f}} 60-100$, and $S_{\mathrm{f}}$ 20-60, were isolated from the plasmas of two hypertriglyceridemic subjects by density-gradient ultracentrifugation in swinging buckets, seven $S_{f}$ subfractions were isolated from another hypertriglyceridemic plasma by zonal ultracentrifugation. The TG: Chol and TG:protein mass ratios and the mean diameters of the swinging bucket isolates were significantly different from each other, e.g., TG:Chol mass ratios of $S_{f}>100, S_{f} 60-100$, and $S_{f}$ 20-60 fractions were 5.1-7.1, 2.7-5.9, and 1.4-2.7, respectively. TG: protein ratios of the same fractions were 9.7-11.5, 6.1-8.8, and 2.8-3.6. This suggested that the desired subfractionation of VLDL indeed had been obtained. Similarly, the composition of the zonal fractions also differed from each other and greatly resembled those reported by Patsch et al. (21) (Table II). Patsch et al. (21) also have demonstrated that zonal VLDL fractions obtained under conditions identical with those used here also differ from each other with respect to $S_{f}$ rates and Stokes radii.

The apparent ApoB contents of the VLDL subfractions, as determined by the TMU technique, ranged from 32 to $79 \%$ of VLDL-protein for the highest to the lowest $\mathrm{S}_{\mathrm{f}}$ fraction (Tables III and IV). (By comparison, $98 \%$ of LDL-protein [ $d 1.025-1.050]$ and $<2 \%$ of HDL protein [ $d$ 1.085-1.195] were TMU precipitable.) However, the amounts of ApoC relative to ApoE, by isoelectric focusing, were the same or increased in the $\mathrm{S}_{\mathrm{f}}$ fractions. (Dye uptake ratios of ApoC:ApoE were $1.8,2.0,1.8,1.8,2.1$, and 2.8 for $\mathrm{VLDL}_{1-6}$ of Table IV, respectively.) Thus, there appeared to be selective increases in ApoB and drops in $\mathrm{ApoC}$ and $\mathrm{ApoE}$ as $S_{\mathrm{f}}$ rates fell.

Immunoreactivities of VLDL fractions isolated from plasma. Those assays that contained anti-LDL antisera (R71, R124, R198) underestimated the ApoB con-

TABLE III

ApoB in Human VLDL Subfractions Isolated in a Swinging Bucket Rotor

\begin{tabular}{|c|c|c|c|c|c|c|c|c|}
\hline \multirow[b]{3}{*}{ S, subfractions } & & & \multicolumn{3}{|c|}{ Anti-LDL } & \multicolumn{3}{|c|}{ Anti-VLDL-ApoB } \\
\hline & \multicolumn{2}{|l|}{ TMU precipitable } & \multicolumn{2}{|c|}{ R71 } & \multirow{2}{*}{$\begin{array}{c}\text { R124 } \\
1\end{array}$} & \multicolumn{2}{|c|}{ R161 } & \multirow{2}{*}{$\begin{array}{c}\text { R162 } \\
1\end{array}$} \\
\hline & VLDL preparation No.... 1 & 2 & 1 & 2 & & 1 & 1 & \\
\hline & & $\%$ of protein & \multicolumn{6}{|c|}{$\%$ of protein } \\
\hline$S_{f}>100$ & 32 & 52 & $17(53)$ & $24(46)$ & $18(56)$ & 35 (109) & $56(108)$ & $28(88)$ \\
\hline$S_{f} 60-100$ & 43 & 64 & $22(51)$ & $39(61)$ & $24(56)$ & $47(109)$ & $67(105)$ & $37(86)$ \\
\hline$S_{f} 20-60$ & 62 & 79 & $48(78)$ & $63(80)$ & $43(70)$ & $69(111)$ & $83(105)$ & $63(102)$ \\
\hline
\end{tabular}

VLDL density subfraction preparations 1 and 2 (Table II) isolated by density-gradient ultracentrifugation in an SW41 rotor were used in these experiments. VLDL protein was determined by the method of Lowry et al. (29). ApoB contents were measured by radioimmunoassay (RIA) using the antisera as described in Table I and the text. The fraction of VLDL protein insoluble in 50\% TMU was also determined. The insoluble fraction is thought to represent ApoB. Results are ApoB (RIA) as percentage of total protein (e.g., $S_{f}>100=A p o B \times 100 \div S_{f}>100$ protein), and ApoB (RIA) as percentage of TMU-precipitable fraction $($ RIA $\times 100 \div$ TMU); the latter in parentheses. 
TABLE IV

ApoB in VLDL Subfractions Isolated from Plasma by Zonal Ultracentrifugation

\begin{tabular}{|c|c|c|c|c|c|}
\hline & \multirow{2}{*}{$\begin{array}{c}\text { TMU } \\
\text { precipitable }\end{array}$} & \multicolumn{2}{|c|}{ Anti-LDL } & \multicolumn{2}{|c|}{ Anti-VLDL-ApoB } \\
\hline & & R71 & R198 & R161 & R 162 \\
\hline & $\%$ of protein & \multicolumn{4}{|c|}{$\%$ of protein } \\
\hline $\mathrm{VLDL}_{1}$ & 32 & $19(59)$ & $21(65)$ & $30(94)$ & $26(80)$ \\
\hline $\mathrm{VLDL}_{2}$ & 40 & $29(72)$ & $32(71)$ & 43 (107) & $33(82)$ \\
\hline $\mathrm{VLDL}_{3}$ & 44 & $41(93)$ & $31(89)$ & $5 \mathrm{I}(115)$ & $39(88)$ \\
\hline $\mathrm{VLDL}_{4}$ & 53 & $46(88)$ & $48(89)$ & 57 (107) & $46(86)$ \\
\hline $\mathrm{VLDL}_{5}$ & 62 & $59(95)$ & $55(88)$ & $60(96)$ & $53(85)$ \\
\hline $\mathrm{VLDL}_{6}$ & 68 & $67(98)$ & $63(93)$ & $74(108)$ & $63(93)$ \\
\hline $\mathrm{VLDL}_{7}$ & 77 & $68(88)$ & $61(80)$ & $77(100)$ & $65(84)$ \\
\hline
\end{tabular}

VLDL density subfractions were isolated from the plasma of a subject with Type IV hyperlipoproteinemia in Ti 14 zonal rotor. Results are expressed as in Table III.

tents of each $\mathrm{S}_{\mathrm{f}}$ fraction in comparison with the TMU technique (Fig. 3, Tables III and IV). The greatest degree of underestimation occurred with the fastest floating fractions and the least with the slowest fractions. In contrast, the radioimmunoassays that contained anti-ApoB antisera (R161, R162) appeared to detect more ApoB in each $S_{f}$ subfraction, and the amounts of ApoB detected were more comparable with the amounts detected by the TMU procedure. Similar results were obtained with another VLDL preparation isolated by the zonal technique (not shown).

VLDL interactions with skin fibroblasts. The abilities of LPL-treated VLDL preparations to compare with ${ }^{125} \mathrm{I}-\mathrm{LDL}$ for uptake and degradation by fibroblasts at $37^{\circ} \mathrm{C}$ was compared with the activities of control VLDL incubated without LPL (Fig. 4) or with inactive LPL (not shown). For these experiments, small aliquots $(10-250 \mu \mathrm{l})$ of the incubation mixtures were added directly to the media bathing the cells. LPL treatment increased the competitive capacities of VLDL preparations. For the four $S_{\mathrm{f}}>100$ (swinging bucket) VLDL preparations studied. Two to five times as much control VLDL protein as LPL-treated VLDL protein was required to obtain equivalent degrees of inhibition of ${ }^{125}$ I-LDL uptake or degradation. To control for any effects of LPL in the VLDL-LPL incubation mixture on the cells themselves, cell monolayers were preincubated for $4 \mathrm{~h}$ at $37^{\circ} \mathrm{C}$ with the maximum amounts of LPL which would have been added along with the LPL-treated VLDL. Cells were washed with saline and the uptake and degradation of ${ }^{125}$ I-LDL were assessed. Results differed from those of non-LPL control cells by $<10 \%$. LPL-treated and control VLDL were also filtered on a column of Sepharose 2B in an attempt to separate lipoproteins from LPL or from any smaller catabolic products (e.g., FFA, PL) before incubating

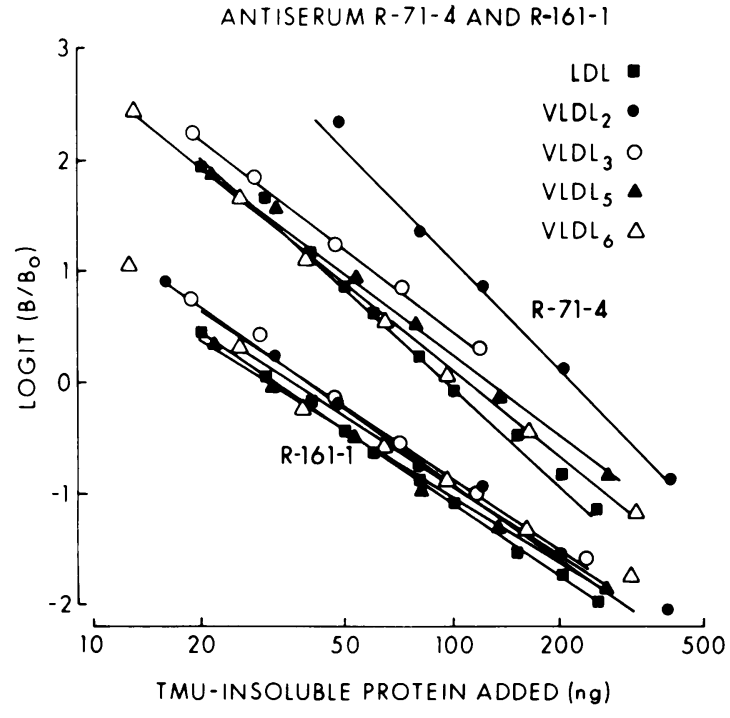

Figure 3 Competitive displacement curves produced by VLDL subfractions isolated from a hypertriglyceridemic plasma. Two assays are shown: one contained R71-4, an antiLDL antiserum; the other contained R161-1, an anti-VLDLApoB antiserum. ${ }^{125} \mathrm{I}-\mathrm{LDL}, \mathrm{LDL}$ standard, and $\mathrm{VLDL}_{1-7}$ were included in each assay. The ApoB content of each fraction was assessed by TMU $(34,35)$ and is shown on the abscissa. For the sake of clarity only $\mathrm{VLDL}_{2,3,5,6}$ are shown. $S_{\mathrm{f}}$ rates and sizes decrease from $\mathrm{VLDL}_{1}$ to $\mathrm{VLDL}_{7}$. It is clear that in the R71-4 assay, the larger $S_{f}$ fractions are less competitive vs. ${ }^{125} \mathrm{I}-\mathrm{LDL}$ than are the smaller fractions per unit of TMU-insoluble protein (ApoB). But in the R161-1 assay all fractions are nearly equivalent in activity. Logit $B / B_{0}$ $=\log \mathrm{B} / \mathrm{B}_{0} / \mathbf{l}-\mathrm{B} / \mathrm{B}_{0}$, where $\mathrm{B}_{0}=$ counts per minute bound ${ }^{125} \mathrm{I}-$ LDL in the absence of LDL or VLDL and $B=$ counts per minute bound ${ }^{125} \mathrm{I}-\mathrm{LDL}$ in the presence of $\mathrm{LDL}$ or VLDL.

the VLDL with cells. The column-filtered, LPL-treated VLDL was four times more effective than the columnfiltered control VLDL in competing with ${ }^{125}$ I-LDL for cellular binding, uptake, and degradation.

The cell surface binding properties of the VLDL lipolysis products isolated by zonal ultracentrifugation (Fig. 2) were tested in competitive assays carried out at $4^{\circ} \mathrm{C}$ (Fig. 5). Binding was inversely related to $S_{\mathrm{f}}$ rate (and size), even when expressed on the basis of TMUinsoluble protein. There was a direct relationship between the competitiveness of the VLDL fractions vs. ${ }^{125}$ I-LDL, for bindng to the LDL receptors on the one hand and for binding to anti-ApoB antibodies on the other (compare Figs. 1 and 5).

The direct uptake and degradation of LPL-treated VLDL by cultured fibroblasts was evaluated next (Fig. 6). VLDL was isolated by ultracentrifugation at $d 1.006$, iodinated with ${ }^{125} \mathrm{I}-\mathrm{Cl}(39,40)$, and incubated with unlabeled high density lipoprotein (HDL) ( $d$ 1.0631.19) for $2 \mathrm{~h}$ at $37^{\circ} \mathrm{C}$ to dilute out any ApoC which had become labeled in VLDL by exchange with the "cold" ApoC of HDL. The HDL protein:VLDL protein mass 

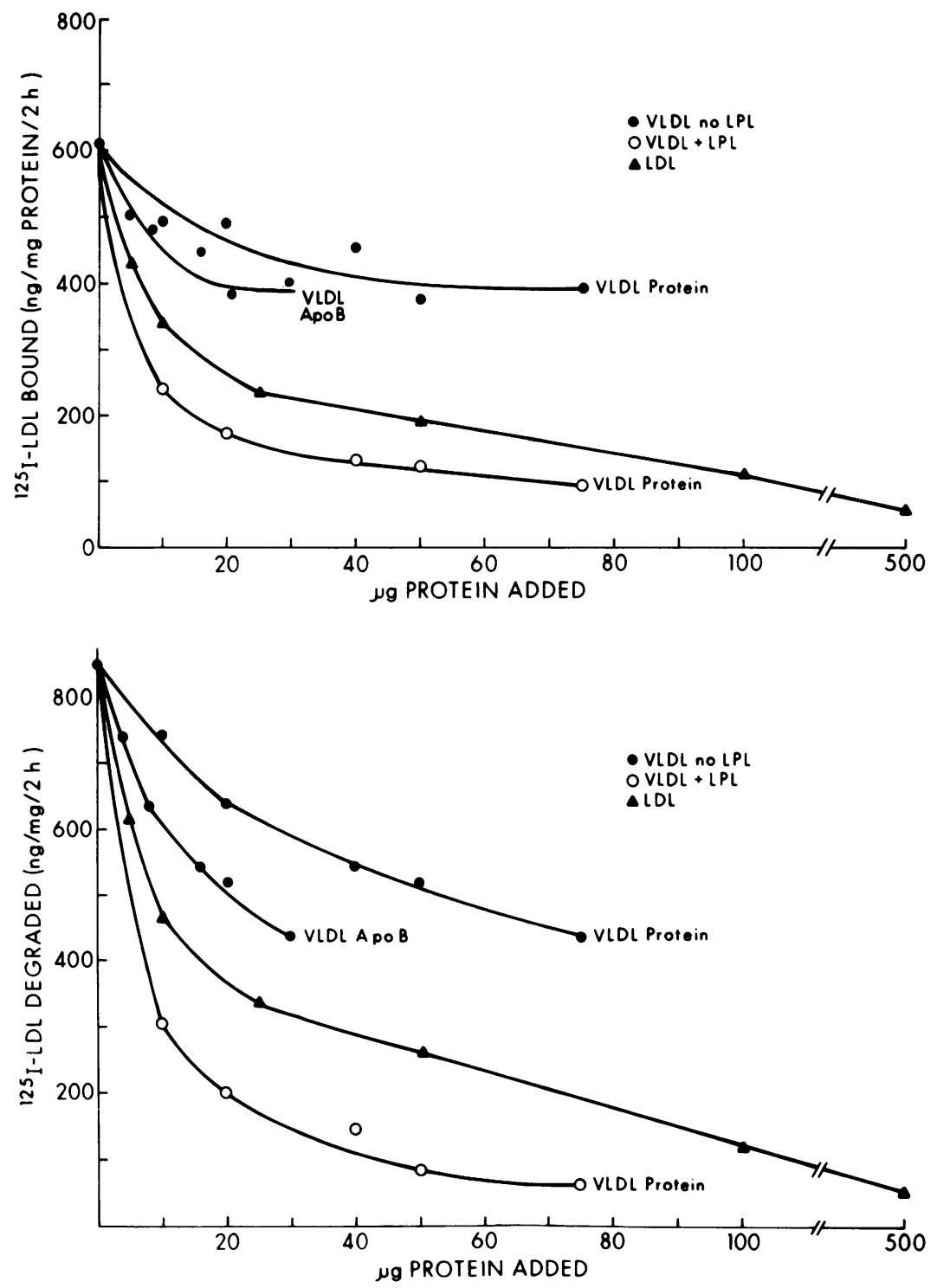

FIgURE 4 The effects of lipolysis of VLDL on its ability to compete with ${ }^{125}$ I-LDL for uptake and degradation by human fibroblasts. LPL-treated or control aliquots of preparation " $d$ " of Table I or "cold" LDL were added to fibroblast cultures that had been grown in lipoprotein-deficient medium for $24 \mathrm{~h} .5 \mu \mathrm{g} / \mathrm{ml}$ of ${ }^{125} \mathrm{I}-\mathrm{LDL}(87 \mathrm{cpm} / \mathrm{ng})$ was also present in the media. The cell-associated ${ }^{125} \mathrm{I}-\mathrm{LDL}$ counts were determined $2 \mathrm{~h}$ later. These contain counts bound to the surface and internalized by the cells. The VLDL-ApoB curve gives the results for the control VLDL when the VLDL added to the cultures is quantified in terms of its contents of ApoB, rather than its total protein.

ratio during this incubation was 50:1. At the end of incubation, the VLDL-HDL mixture was ultracentrifuged at $d 1.006$ for $10^{8} \mathrm{~g} / \mathrm{min}$ in a 40.3 Beckman rotor. VLDL was removed by pipetting. $87 \%$ of the ${ }^{125}$ I-label in this preparation was precipitable by TMU and $8 \%$ was in lipid, which suggested that virtually all of the protein label was in ApoB. The ${ }^{125}$ I-VLDL was split into two aliquots, one aliquot was incubated without
LPL and the other with LPL for $2 \mathrm{~h}$ at $37^{\circ} \mathrm{C}$. After incubation, VLDL was reisolated by column chromatography on Sepharose 2B as described above. The specific radioactivity of the ${ }^{125} I-A p o B$ in VLDL was $122 \mathrm{cpm} / \mathrm{ng}$ and had not been altered by incubation. TG had decreased from 191 to $110 \mathrm{mg} / \mathrm{dl}$. When cultured fibroblasts were incubated in the presence of $5 \mu \mathrm{g} / \mathrm{ml}$ of the LPL-treated and control VLDL-125I-ApoB 


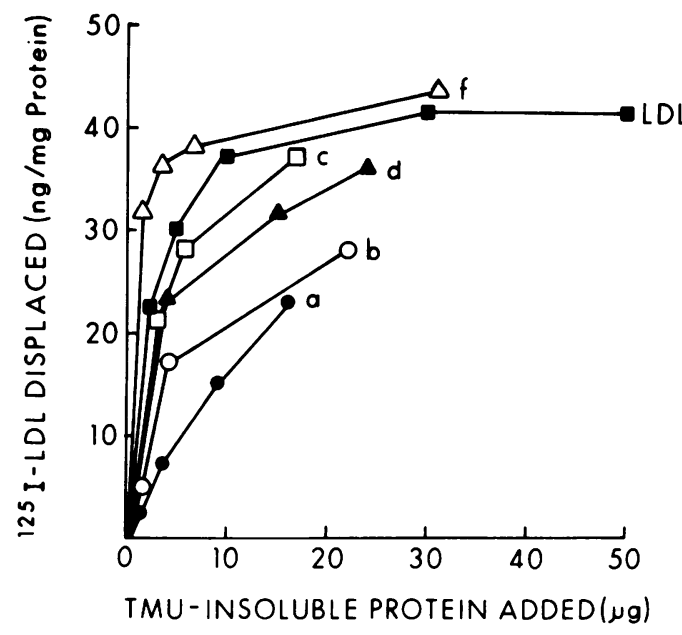

FIGURE $5{ }^{125}$ I-LDL displacement by VLDL-lipolysis products. Effect of lipolysis on the binding of VLDL to cellular surface receptors. Starting $\mathrm{S}_{\mathrm{f}}>150$ VLDL, the lipolysis products $\left(\mathrm{VLDL}_{a-f}\right)$ shown in Fig. 2, or "cold" LDL were incubated with $5 \mu \mathrm{g} / \mathrm{ml}$ of ${ }^{125} \mathrm{I}-\mathrm{LDL}$ at $4^{\circ} \mathrm{C}$ for $4 \mathrm{~h}$. The cells were normal human skin fibroblasts which had been grown in LPDS for $24 \mathrm{~h}$ before the experiment. The ApoB contents of each fraction were determined by TMU $(34,35)$ and are expressed as TMU-soluble protein on the abscissa. It is clear that the competitive capacity of VLDL is inversely related to $S_{f}$ rate (or size) at any given $A p o B$ concentration and is, in fact, directly related to the degree of lipolysis.

for 1, 2, and $4 \mathrm{~h}$ (Fig. 6), the LPL-treated preparation was taken up and degraded at a much greater rate than was the control preparation.

Finally, competitive binding assays were carried out at $4^{\circ} \mathrm{C}$ using the zonal subfractions of VLDL isolated from plasma (Table IV), which were incubated with cultured fibroblasts, and ${ }^{125}$ I-LDL (Fig. 7). Here too, as in the case of the LPL-treated VLDL (Figs. 2 and 5), the competitiveness of the VLDL subfractions was inversely related to their $S_{f}$ rates, and again there were strong relationships between the ApoB immunoreactivities and the cell reactivities of VLDL preparations (Table IV, Figs. 3 and 7). Those fractions which competed most effectively with ${ }^{125}$ I-LDL for limiting amounts of anti-ApoB antibodies also competed most effectively with ${ }^{125}$ I-LDL for cellular LDL receptors.

\section{DISCUSSION}

Partially catabolized TG-rich lipoproteins are more effectively removed by arterial smooth muscle cells, fibroblasts, and liver than are more "intact" lipoproteins (7-12). LPL, the enzyme responsible for the lipolysis of these particles, produces particles which are smaller in size, depleted in TG, and relatively rich in Chol esters, PL, and ApoB (3-6). We now demonstrate that, in addition, VLDL preparations treated with LPL consistently showed increases in the immunologic
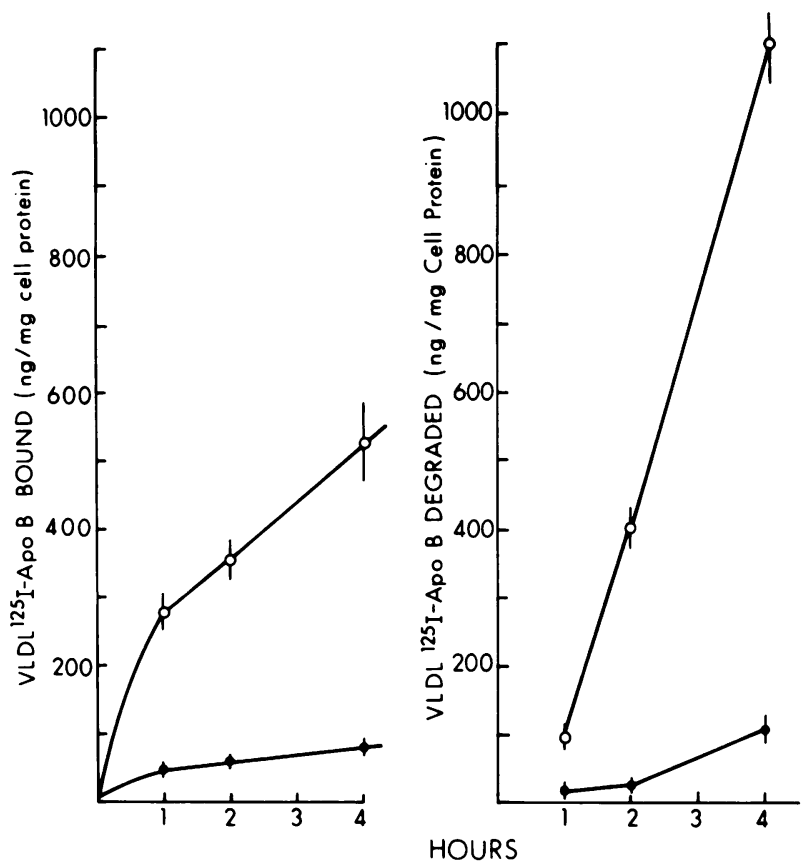

Figure 6 The binding and degradation of LPL-treated ${ }^{125}$ I-VLDL by cultured human fibroblasts. VLDL-125I-labeled in its ApoB moiety (VLDL- ${ }^{125} \mathrm{I}-\mathrm{ApoB}$ ) was incubated with LPL for $2 \mathrm{~h}$, reisolated by Sepharose 2B chromatography, and added to cultured fibroblasts. The same VLDL- ${ }^{125} I-A p o B$, incubated without LPL, was added to another set of culture dishes. The concentration of VLDL- ${ }^{125} \mathrm{I}-\mathrm{ApoB}$ was $5 \mu \mathrm{g} / \mathrm{ml}$ (12.5 $\mu \mathrm{g} / \mathrm{ml}$ VLDL protein, $40 \%$ of which was TMU precipitable). (O)LPL-treated; (O)control. Results are mean \pm 1 SD of incubations carried out at $37^{\circ} \mathrm{C}$ in quintuplicate.

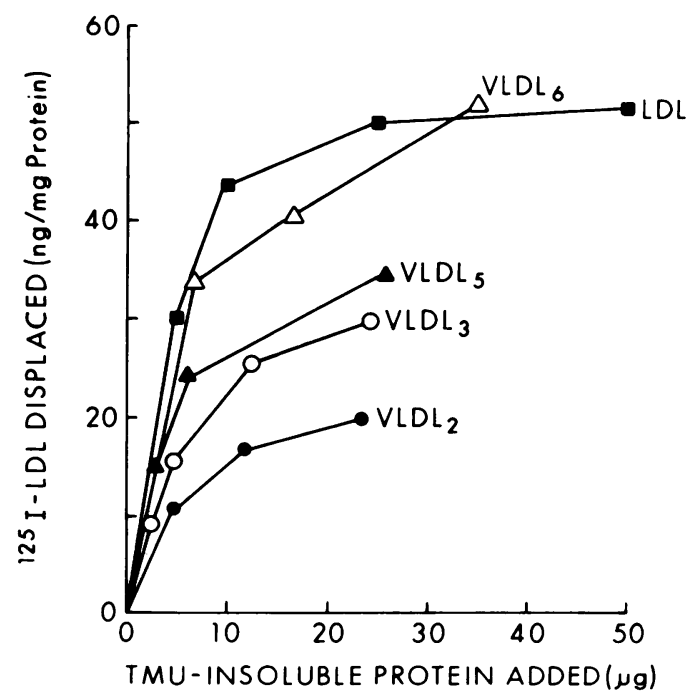

FIGURE 7 125I-LDL displacements by VLDL subfractions. The binding of VLDL subfractions isolated from plasma to cellular surface receptors. VLDL subfractions, $\mathrm{VLDL}_{1-7}$, isolated from plasma by zonal ultracentrifugation (Table IV) were incubated at $4^{\circ} \mathrm{C}$ with normal fibroblasts as in Fig. 5. Competitiveness was inversely related to $S_{f}$ rate and size. (For the sake of clarity only VLDL $_{2,3}, 5,6$ are shown.) 
reactivities of their ApoB moieties (Table I, Figs. 1 and 2). Comparable immunologic differences were also found in the immunoreactivities of ApoB in the VLDL density subfractions isolated from these plasma (Table III). Because faster floating larger VLDL are thought to be converted to slower floating smaller VLDL in vivo $(5,42)$, LPL catalyzed lipolysis alone appears to be sufficient to explain the changed ApoB immunoreactivity found in vivo.

The fact that some antisera were and others were not able to detect changes in $\mathrm{ApoB}$ immunoreactivity is interpreted as being because of the fact that antiApoB and anti-LDL antisera contained populations of antibodies with different ranges of specificities vs. ApoB. This is not too surprising because isolated ApoB and the ApoB in holo-LDL, both of which were used on the production of antisera, need not be identical immunogens. Analogous differences in antiserum specificity have been reported for antisera produced against isolated ApoA-I and HDL-associated ApoA-I $(43,44)$.

The altered immunoreactivity of $\mathrm{ApoB}$ was not a result of changes in VLDL size (i.e., steric hindrance) alone because whereas some antisera were able to detect differences between control VLDL and LPLtreated VLDL, others were unable to do so. Had size alone been the crucial factor, all antisera should have yielded similar results. The change in immunoreactivity also did not appear to be a result of proteolysis. The remaining possibilities are that as lipids and apoproteins were removed during lipolysis, "masked" areas of ApoB became uncovered, or that, as the larger VLDL spheres were converted to smaller spheres, the concentrations, conformation, or dispositions of $\mathrm{ApoB}$ on the surfaces of the particles were altered to adjust to the new surface geometry and composition of the particles. It is likely that several of these events were occurring simultaneously. Compatible conclusions were reached by Gianturco et al. (45) and Catapano et al. (46) to account for their findings of greater effectiveness of VLDL isolated from hyperlipemic (vs. normal) plasma and of LPL-treated VLDL (vs. untreated VLDL) in suppressing $\beta$-OH-methyl $\beta$-glutaryl coenzyme A reductase in cultured fibroblasts.

Alterations in the immunoreactivity of $\mathrm{ApoE}$, another protein recognized by cells, were not found. This does not exclude the existence of LPL-induced changes in ApoE because only two anti-ApoE antisera were used. Perhaps other antisera directed against VLDL-associated ApoE could have detected some differences. However, it should be noted that in contrast with ApoB, which became "concentrated" on the smaller particles, the ApoE contents of the slower floating smaller fractions were less than those of the faster, larger fractions. Thus, the ApoE concentration at the surfaces of the particles should be considerably less than the surface concentrations of ApoB.
The changes in ApoB immunoreactivity were accompanied by striking increases in the abilities of LPL-treated particles to compete with ${ }^{125}$ I-LDL for binding, uptake, and degradation by fibroblasts. Those fractions that competed most effectively with ${ }^{125}$ I-LDL for binding to anti-ApoB antibody also competed most effectively with ${ }^{125}$ I-LDL for binding to cellular LDLreceptors. In addition, LPL-treated VLDL-125I-ApoB was taken up and degraded much more avidly than were the control preparations. Although we have not ruled out the effects of other apoproteins (e.g., ApoE), the coincidence of changes in the immunoreactivity of VLDL-ApoB and the enhanced recognition of VLDL by cells suggests that the lipolysis-induced alterations in the disposition of ApoB on the surfaces of VLDL may be related to the enhanced interactions of the partially degraded VLDL with cells.

\section{ACKNOWLEDGMENTS}

We are grateful for the technical assistance of Joseph Leykam, Robert Roy, and Pat Reilly.

This research has been supported by National Institutes of Health contract NO1-HV-2-2916-L, the Lipid Research Clinics Project, and National Institutes of Health grant HL 15308.

\section{REFERENCES}

1. Gangel, A., and R. K. Ockner, 1975. Intestinal metabolism of lipids and lipoproteins. Gastroenterology. 68: 167-186.

2. Glaumann, H., A. Bergstrand, and J. L. E. Ericsson. 1975. Studies on the synthesis and intracellular transport of lipoprotein particles in rat liver. J. Cell Biol. 64: 356-377.

3. Mjos, O. D., O. Faergeman, R. L. Hamilton, and R. J. Havel. 1975. Characterization of remnants produced during the metabolism of triglyceride rich lipoproteins of blood plasma and intestinal lymph in the rat. J. Clin. Invest. 56: 603-615.

4. Redgrave, T. G. 1970. Formation of cholesteryl ester rich particulate lipid during metabolism of chylomicrons. J. Clin. Invest. 49: 465-471.

5. Chajek, T., and S. Eisenberg. 1978. Very low density lipoprotein. Metabolism of phospholipids, cholesterol, and apolipoprotein $C$ in the isolated perfused rat heart. J. Clin. Invest. 61: 1654-1655.

6. Higgins, J. M., and C. J. Fielding. 1975. Lipoprotein lipase. Mechanism of formation of triglyceride rich remnant particles from very low density lipoproteins and chylomicrons. Biochemistry. 14: 2288-2292.

7. Bierman, E. L., S. Eisenberg, O. Stein, and Y. Stein. 1973. Very low density lipoprotein "remnant" particles: uptake by aortic smooth muscle cells in culture. Biochim. Biophys. Acta. 329: 162-169.

8. Faergeman, O., and R. J. Havel. 1975. Metabolism of cholesteryl esters of rat very low density lipoproteins. J. Clin. Invest. 55: 1210-1218.

9. Faergeman, O., T. Sata, J. P. Kane, and R. J. Havel. 1975. metabolism fo apoprotein B of plasma very low density lipoprotein in the rat. J. Clin. Invest. 56: 1396-1403.

10. Cooper, A. D. 1977. The metabolism of chylomicron remnants by isolated perfused rat liver. Biochim. Biophys. Acta. 488: 464-474.

11. Floren, C. H., and A. Nilsson. 1977. Binding, interiorization and degradation of cholesteryl ester-labelled chylo- 
micron-remnant particles by rat hepatocyte monolayers. Biochem. J. 168: 484-494.

12. Floren, C. H., and A. Nilsson. 1977. Degradation of chylomicron remnant cholesteryl ester by rat hepatocyte monolayers. Inhibition of chloroquine and colchicine. Biochem. Biophys. Res. Commun. 74: 520-528.

13. Goldstein, J. L., and M. S. Brown. 1977. The low-density lipoprotein pathway and its relation to atherosclerosis. Annu. Rev. Biochem. 46: 897-930.

14. Shireman, R., L. L. Kilgore, and W. R. Fisher. 1977. Solubilization of apolipoprotein B and its specific binding by the cellular receptor for low density lipoproteins. Proc. Natl. Acad. Sci. U. S. A. 74: 5150-5154.

15. Steinberg, D., P. J. Nestel, D. B. Weinstein, M. RemautDesmeth, and C. M. Chang. 1978. Interactions of native and modified human low density lipoproteins with human skin fibroblasts. Biochim. Biophys. Acta. 528: 199-212.

16. Innerarity, T., and R. W. Mahley. 1978. Enhanced binding by cultured human fibroblasts of ApoE-containing lipoproteins as compared with low density lipoproteins. Biochemistry. 17: 1440-1447.

17. Scanu, A. M., C. Edelstein, and P. Keim. 1975. Serum lipoproteins. In The Plasma Proteins. F. W. Putnam, editor. Academic Press, Inc., New York. 1: 317-391.

18. Gotto, A. M., W. V. Brown, R. I. Levy, M. E. Birnbaumer, and D. S. Fredrickson. 1972. Evidence for the identity of the major apoprotein in low density and very low density lipoproteins in normal subjects and patients with familial hyperlipoproteinemia. J. Clin. Invest. 51: 14861494.

19. Schonfeld, G., R. S. Lees, P. K. George, and B. Pfleger. 1974. Assay of total plasma apolipoprotein B concentration in human subjects. J. Clin. Invest. 53: 1458-1467.

20. Lindgren, F. T., L. C. Jensen, and F. T. Hatch. 1975. The isolation and quantitative analysis of serum lipoproteins. In Analysis of Lipids and Lipoproteins. E. A. Perkins, editor. American Oil Chemists' Society, Champaign, Ill. 181-274.

21. Patsch, W., J. R. Patsch, G. M. Kostner, S. Sailer, and $\mathrm{H}$. Braunsteiner. 1978. Isolation of subfractions of human very low density lipoproteins by zonal ultracentrifugation. J. Biol. Chem. 253: 4911-4915.

22. Iverius, P. H., and A. M. Ostlund-Lindqvist. 1976. Lipoprotein lipase from bovine milk. J. Biol. Chem. 251: $7791-7795$.

23. Carlson, L. A. 1963. Determination of serum triglycerides. J. Atheroscler. Res. 3: 334-336.

24. Manual of Laboratory Operations, Lipid Research Clinics Program. 1974. Lipid and Lipoprotein Analysis. Department of Health, Education, and Welfare Publication 75-628. Volume 1.

25. Röschlau, P., E. Bernt, and W. Gruber. 1974. Enzymatische Bestimmung des gesamt-cholesterin im serum. J. Clin. Chem. Clin. Biochem. 12: 403-407.

26. Patsch, W., S. Sailer, and H. Braunsteiner. 1976. An enzymatic method for the determination of the initial cholesterol esterification rate in human plasma. J. Lipid Res. 17: $182-185$.

27. Bartlett, G. R. 1959. Phosphorous assay in column chromatography. J. Biol. Chem. 234: 466-468.

28. Bensadoun, A., and D. Weinstein. 1976. Assay of proteins in the presence of interfering materials. Anal. Biochem. 70: 241-250.

29. Lowry, O. H., N. J. Rosebrough, A. L. Farr, and R. J. Randall. 1951. Protein measurement with the Folin phenol reagent. J. Biol. Chem. 193: 265-275.
30. Weidman, S. W., B. Suarez, J. M. Falko, J. L. Witztum, J. Kolar, M. Raben, and G. Schonfeld. 1979. Type III hyperlipoproteinemia: development of a VLDL ApoB gel isoelectric focusing technique and application in family studies. J. Lab. Clin. Med. 93: 549-569.

31. Schonfeld, G., R. S. Lees, P. K. George, and B. Pfleger. 1974. Assay of total plasma apolipoprotein B concentration in human subjects. J. Clin. Invest. 53: 1458-1467.

32. Brown, W. V., R. I. Levy, and D. S. Fredrickson. 1969. Studies of the proteins in human plasma very low density lipoproteins. J. Biol. Chem. 244: 5687-5694.

33. Herbert, P. N., R. S. Shulman, R. I. Levy, and D. S. Fredrickson. 1973. Fractionation of the C-apoproteins from human plasma very low density lipoproteins. J. Biol. Chem. 248: 4941-4946.

34. Kane, J. P. 1973. A rapid electrophoretic technique for identification of subunit species of apoproteinsin serum lipoproteins. Anal. Biochem. 53: 350-364.

35. Kane, J. P., T. Sata, R. L. Hamilton, and R. J. Havel. 1975. Apoprotein composition of very low density and lipoproteins of human serum. J. Clin. Invest. 56: 1622-1634.

36. Weber, K., and M. Osborne. 1969. The reliability of molecular weight determinations by dodecyl sulfatepolyacrylamide gel electrophoresis. J. Biol. Chem. 244: 4406-4412.

37. Goldstein, J. L., and M. S. Brown. 1974. Binding and degradation of low density lipoproteins by cultured human fibroblasts. J. Biol. Chem. 249: 5153-5162.

38. Ostlund, R. E., Jr., B. Pfleger, and G. Schonfeld. 1979. Role of microtubules in low density lipoprotein processing by cultured cells. J. Clin. Invest. 63: 75-84.

39. McFarlane, A. S. 1956. Labelling of plasma protein with radioactive iodine. Biochem. J. 62: 135-143.

40. Langer, T., W. Strober, and R. I. Levy. 1972. The metabolism of low density lipoprotein in familial type II hyperlipoproteinemia. J. Clin. Invest. 51: 1528-1536.

41. Goldstein, S., and M. J. Chapman. 1979. Radioimmunological study of the surface protein of the human serum low density lipoprotein: comparison of the native particle and the products obtained by tryptic treatment. Biochem. Biophys. Res. Commun. 87: 121-127.

42. Levy, R. I., D. W. Bilheimer, and S. Eisenberg. 1971. The structure and metabolism of chylomicrons and very low density lipoproteins (VLDL). Biochem. Soc. Symp. 33: 3-17.

43. Schonfeld, G., R. A. Bradshaw, and J. Chen. 1976. Structure of high density lipoproteins. The immunologic reactivities of the COOH- and $\mathrm{NH}_{2}$-terminal regions of apolipoprotein A-I. J. Biol. Chem. 251: 3921-3926.

44. Schonfeld, G., J. Chen, and R. G. Roy. 1977. Use of antibody specificity to study the surface disposition of apoprotein A-I on human high density lipoproteins. J. Biol. Chem. 252: 6655-6659.

45. Gianturco, S. H., A. M. Gotto, Jr., R. L. Jackson, J. R. Patsch, H. D. Sybers, O. D. Taunton, D. L. Yéshurun, and L. C. Smith. 1978. Control of 3-hydroxy-3-methylglutarylCoA reductase activity in cultured human fibroblasts by very low density lipoproteins of subjects with hypertriglyceridemia. J. Clin. Invest. 61: 320-328.

46. Catapano, A. L., S. H. Gianturco, P. K. T. Kinnunen, S. Eisenberg, A. M. Gotto, Jr., and L. C. Smith. 1979. Suppression of 3-hydroxy-3-methylglutaryl-CoA reductase by low density lipoproteins produced in vitro by lipoprotein lipase action in non-suppressive very low density lipoproteins. J. Biol. Chem. 79: 1007-1009. 